\title{
DESTRINCHANDO OS 13 PORQUÊS: UMA ANÁLISE DOCUMENTAL DA SÉRIE DE STREAMING "13 REASONS WHY"
}

\author{
Thaís Milena Vale de Sousa - Universidade Estadual do Piauí \\ Ana Rosa Rebelo Ferreira de Carvalho - Universidade Estadual do Piauí
}

\begin{abstract}
RESUMO
O presente estudo consiste em uma análise crítica da primeira temporada da série de streaming 13 Reasons Why a partir das orientações propostas pela OMS no guia para os profissionais da mídia. A referida série foi estudada a partir da análise de conteúdo de Bardin. Como resultados, foi possível identificar quatro categorias que se destacam: a) fatores protetivos e fatores de risco do suicídio; b) profissionais de saúde e educação frente ao suicídio; c) luto por suicídio; e d) abordagem da mídia ao suicídio. A partir da análise da série, percebe-se que se trata de uma história fictícia, como apontado no início da série, entretanto, a partir das orientações existentes sobre como a mídia deve abordar a temática do suicídio, é possível constatar que houve várias falhas na forma em que o tema foi explorado, valorizando a função midiática em detrimento da educativa e preventiva. Propomos que a mídia aborde o suicídio de forma a promover a saúde mental e preveni-lo com cuidados como: destacar alternativas ao suicídio, mostrar os fatores de risco e proteção, fornecer informações sobre onde encontrar apoio psicológico, demonstrar empatia aos sobreviventes, explicitar questões de saúde mental e desmitificar esse fenômeno.
\end{abstract}

Palavras-Chave: Suicídio. Luto por suicídio. Mídia.

\begin{abstract}
The present study consists of a critical analysis of the streaming series 13 Reasons Why first season from the guidelines applied by WHO in the guide for media professionals. The series was studied from Bardin's content analysis. As a result, it was possible to identify four categories: a) protective factors and suicide risk factors; b) health and education professionals facing suicide; c) mourning for suicide; and d) media approach to suicide. From the analysis of the series, it is clear that this is a fictitious story, as pointed out at the beginning of the series, however, from the existing guidelines on how the media should approach the subject of suicide, it is possible to see what happened earlier in the series way the theme was explored, valuing a media function over education and prevention. Proposes that the media accept suicide in a way that promotes mental health and avoid them with care such as: alternative suicide changes, display of risk and protective factors, information on where to find psychological support, demonstration of empathy to survivors, explanatory questions mental health and demystify this phenomenon.
\end{abstract}

Keywords: Suicide. Mourning for suicide. Media.

\section{INTRODUÇÃO}

O suicídio é um ato deliberado realizado pelo próprio sujeito, cuja intenção, mesmo que ambivalente e consciente, é a morte, usando um método que ele acredite ser letal. Fazem parte do chamado comportamento suicida os pensamentos, planos e tentativas de suicídio. Esse fenômeno está presente ao longo da história da humanidade e em diversas culturas, sendo 
multifatorial e resultante da interação de fatores psicológicos, biológicos, culturais e socioambientais, não podendo ser reduzido a formas causais e simplistas (ASSOCIAÇÃO BRASILEIRA DE PSIQUIATRIA, 2014).

Segundo Botega (2013), ocorre um suicídio a cada 45 segundos, o que significa que diariamente, 1920 pessoas se suicidam ao redor do mundo, entretanto estima-se que as tentativas de suicídio superem o número de suicídios em pelo menos dez vezes, demonstrando que o fenômeno em questão constitui um problema de saúde pública. No contexto internacional, o Brasil encontra-se entre os dez países que registram os maiores números absolutos de suicídios.

O suicídio constitui um fenômeno multifatorial que, segundo Ferreira Junior (2015), abarca aspectos políticos, econômicos, raciais, de gênero e culturais, além de acarretar grande impacto social, econômico e pessoal. Neste sentido, observa-se que os altos índices de suicídio requerem dos profissionais de saúde, das Instituições de Saúde e do Governo, o reconhecimento da existência dos fatores de riscos e o desenvolvimento de estratégias voltadas para essa problemática, uma vez que, é apontado em diversos estudos, que mortes por suicídio podem ser evitadas a partir de estratégias de promoção e prevenção (BOTEGA, 2014; ARAUJO JÚNIOR, 2014; PARENTE, 2007).

Diante de tal realidade, o Ministério da Saúde estabeleceu as Diretrizes Nacionais para Prevenção do Suicídio em 2006 com o intuito de reduzir as taxas de suicídio, de tentativas de suicídio e de danos decorrentes de comportamento suicidas e autolesivos. De acordo com o Ministério da Saúde (BRASIL, 2006) dentre os principais fatores de riscos para o suicídio destaca-se a presença de transtornos mentais, condições sociodemográficas, psicológicas, condições clínicas incapacitantes, história pregressa de tentativas de suicídio e comorbidades.

Apesar de constituir um caso de Saúde Pública, o suicídio ainda é um tema tabu, pouco discutido na sociedade e quando feito, com bastantes reservas. Na mídia, prevalece o entendimento de que os veículos de comunicação podem precipitar a ocorrência de novos casos, o que gera a insegurança e o receio de se abordar a temática. Entretanto, a mídia constitui um importante instrumento formador de opinião, conceitos e comportamentos. O Instituto de Pesquisa econômica aplicada - IPEA (2013) classifica a mídia como o terceiro maior motivador de suicídios, depois de desemprego e violência, para todos os grupos de pessoas.

Como exemplo desta influência, cita-se o livro "Os Sofrimentos do Jovem Werther", de Johann Wolfgang Goethe, publicado em 1774. Neste livro o personagem principal se apaixona por 
uma mulher que não está ao seu alcance e se mata com um tiro. Após a publicação desse livro, surgiram relatos de jovens que se suicidaram usando o mesmo método, vestidos ao estilo do personagem ou foi encontrado o livro no local da morte. A partir disso, foi criado o termo "Efeito Werther" para designar a imitação de suicídios (OMS, 2000; BOTEGA et al. 2009).

Em 2017, foi lançada em uma provedora global de filmes e séries de televisão via streaming a primeira temporada da série "13 Reasons Why" ("13 Porquês") que tem como tema central o suicídio de uma adolescente que deixa antes de morrer gravações em fitas cassete que revelam os 13 motivos que a levaram a tirar sua própria vida (NETFLIX, 2017). A série é uma adaptação do romance homônimo do escritor Jay Asher publicado em 2007.

Diante da influência da mídia ao evento suicida, a Organização Mundial de saúde (2000) elaborou um documento, produzido por profissionais de saúde, intitulado "Prevenção do suicídio: um manual para os profissionais da mídia", orientando os profissionais a abordar o problema do suicídio de forma apropriada, cuidadosa e potencialmente útil, reconhecendo que a mídia, por ocupar um papel central na sociedade e influenciar atitudes, crenças e comportamentos, além de disseminar informações, pode ser utilizada para a prevenção do suicídio ou, em contrapartida, influenciar na ocorrência de outros casos. Botega et al. (2009) pontua ainda que tal documento constitui um guia de como conduzir notícias ou reportagens envolvendo o suicídio.

Neste contexto, a série "13 Reasons Why", ao abordar o tema do suicídio, tornou-se objeto de discussões. Ao mesmo tempo em que despertou interesse de um grande público de diversas faixas etárias, culturas, crenças e classes sociais e, chamando a atenção para esse fenômeno e fornecendo contatos de onde se pode obter ajuda, a série também foi criticada por diversos profissionais por trazer à tona a discussão apresentada pela OMS (2000), que pontua que a publicação de um suicídio na mídia pode ser uma situação gatilho para outros suicídios.

De tal modo, a perspectiva aqui apresentada, propõe se debruçar sobre a série a partir do conceito de suicídio e questionar em que medida a ficção se distancia ou se afasta da realidade ao retratar o sofrimento vivenciado pelo suicida, sua família e entorno social. Tendo isso em vista, compreendemos que a análise crítica da referida serie, possibilita a desmistificação do tema, a construção de conhecimento e possibilidade de propormos formas de abordar o tema junto ao grande público. Assim, a presente pesquisa busca explorar as relações entre as orientações da OMS sobre o suicídio e a série de streaming "13 Reasons Why", desta forma, pretende-se que os resultados da análise da série possam contribuir em dois âmbitos: primeiro, para a produção do 


\section{CONQGEESOO CIENCIAESOCIEDADE

conhecimento acadêmico sobre como abordar o suicídio na mídia. Segundo, espera-se que os resultados possam ser úteis para a elaboração de propostas de prevenção ao suicídio e promoção de saúde mental.

\section{METODOLOGIA (Ou MATERIAL E MÉTODOS)}

Os documentos pesquisados foram os 13 episódios da série de streaming "13 Reasons Why" (em tradução para o Português, Os 13 Porquês), lançada pela provedora global de filmes e séries via streaming Netflix (2017) mais o episódio "13 Reasons Why: além dos porquês", todos do produtor executivo Brian Yorkey.

Os dados coletados foram estudados a partir da análise de conteúdo de Bardin (2009), que constitui um conjunto de técnicas de análise das comunicações, que por meio de procedimentos objetivos e sistemáticos de descrição do conteúdo e mensagens, obtém indicadores capazes de inferir conhecimentos relativos às condições de produção/recepção dessas mensagens. Para tanto, foi realizada uma análise temática que, de acordo com a autora supracitada, adota o tema como unidade de registro e consiste em descobrir os núcleos de sentido que compõe a comunicação e cuja presença ou frequência de aparição pode significar alguma coisa para o objeto analítico escolhido.

Para isso, a análise ocorreu em três fases, conforme propõe Minayo (2006): pré-análise organização do material a ser analisado, com leitura flutuante da série e das reportagens, relacionando o conteúdo encontrado com os objetivos iniciais da pesquisa; exploração do material - codificação das mensagens, ou seja, transformação sistemática do conteúdo em agrupamentos de unidades que permitam uma descrição exata que represente as características relevantes do conteúdo, a partir da análise temática; e tratamento dos resultados obtidos e interpretação inferência dos resultados da pesquisa com base no quadro teórico e bibliográfico da literatura, desvelando-se o conteúdo subjacente ao que está sendo manifesto.

\section{RESULTADOS E DISCUSSÃO}


A partir da análise realizada, foi possível identificar quatro categorias que se destacaram. Assim, as mesmas foram divididas para facilitar a compreensão, entretanto, elas conversam entre si.

\section{EIXO TEMÁTICO 1 - FATORES PROTETIVOS E FATORES DE RISCO DO SUICÍDIO}

Ao longo da série, foram identificados diversos fatores de risco do suicídio, como bullying (que ocorre ao longo da série), assédio (Bryce aperta as nádegas de Hannah), abuso sexual (quando Bryce abusa sexualmente de Hannah no episódio 12 e de Jéssica no episódio 9), situações traumáticas (Hannah presenciou, no episódio 9, Jessica sendo abusada sexualmente), sentimento de desesperança (mais claramente evidenciado quando Hannah perde o dinheiro de seus pais no episódio 12 e diz que "a vida das pessoas seria melhor sem ela"), ausência de apoio social (Hannah não mantém nenhuma amizade duradoura, Clay tem dificuldades com relacionamentos interpessoais, Alex não se envolve efetivamente com os amigos, entre outros), acesso a meios letais (como armas de fogo e lâminas), comportamentos de risco (como uso de álcool e maconha), comportamento suicida (visto em Hannah ao longo dos episódios, em Justin, Clay e Alex) e falta de apoio familiar (Bryce mora praticamente só pois os pais estão sempre viajando, Justin foi expulso de sua casa pelo padrasto e falta de diálogo entre as famílias).

Para Botega (2015), os fatores de risco têm intensidade e duração variadas, e exercem sua influência em diversas fases da vida. No caso de Hannah, foi possível observar um entrelaçamento de fatores e situações que contribuíram para que ela escolhesse morrer.

O estado mental de Hannah parecia marcado pela distorção que o seu sofrimento emocional the causou e, com isso, o seu funcionamento mental girava em torno de sentir o sofrimento como intolerável, como algo que ela não conseguiria suportar e que não teria fim. Essa característica de rigidez torna o comportamento inflexível quanto à decisão de se matar (ABP, 2014).

Quanto aos fatores de proteção, como boas relações interpessoais, rede social que proporcione apoio e práticas coletivas, não foram evidenciadas de forma significativas, com exceção de práticas coletivas, quando Hannah tenta participar de um grupo de poesia no episódio 8, mas acaba saindo depois de um poema seu ter sido publicado na revista da escola por um dos membros (Ryan) sem sua autorização, o que fez ela se sentir traída e exposta.

A personagem apresentava muitos fatores de risco, entretanto, eles não foram percebidos pelos demais personagens no decorrer da série e não foram evidenciados na trama como uma 


\section{CONGEESSO CIENCIAESOCIEDADE \\ Inovação, Diversidaale e Sustentahilitilaile}

forma de chamar atenção para a identificação de sintomas e possível prevenção. A única vez que algum personagem percebeu o quanto ela estava sofrendo, foi através do bilhete lido pela professora na aula de Comunicação, entretanto, não se identificou o autor do bilhete e nada foi feito a respeito, demonstrando clara negligência. Nem a escola, nem os pais e nem os colegas de escola de Hannah perceberam os sinais que ela dava de que não estava bem.

Quanto aos fatores protetivos, a série não os enfatiza, mas seria interessante que o fizesse, para mostrar ao público as possíveis proteções, como integração e bons relacionamentos em grupos sociais, bom relacionamento interpessoal, apoio em situações de necessidade, rede social que propicia apoio prático e emocional, disponibilidade de serviços de saúde mental, práticas religiosas, práticas coletivas e boa qualidade de vida (ABP, 2014; BOTEGA, 2015).

\section{EIXO TEMÁTICO 2 - PROFISSIONAIS DE SAÚDE E EDUCAÇÃO FRENTE AO SUICÍDIO}

Foi identificado o despreparo profissional da escola ao lidar com o suicídio e o sofrimento dos alunos (a escuta não se mostrou efetiva e nem acolhedora e a abordagem do suicídio ocorreu unicamente por meio de cartazes, que não se mostraram muito ineficazes) e a falta de treinamento de habilidades pessoais e sociais (o mais próximo disso ocorre nas aulas de Comunicação, mas ainda assim parece distante dos alunos e de suas realidades e não os envolve).

No que tange ao acolhimento dos alunos, é necessário o profissional estar disponível para se aproximar do lugar onde o sujeito está, desenvolver uma atitude empática, pois, através dessa disponibilidade interpessoal, poderá emergir a esperança de que o cliente possa reconhecer suas potencialidades e, assim, ampliar suas formas de enfrentamento ao sofrimento (FUKUMITSU, 2014).

É importante ressaltar que na prevenção ao suicídio o trabalho dever ser realizado com a família, psiquiatras, enfermeiros e secretarias de saúde, educação e cultura, em um trabalho conjunto (PIEDRAHITA; PAZ; ROMERO, 2012; FUKUMITSU, 2014).

A escola, com seu papel de formação e informação, deve facilitar a comunicação e o diálogo sobre o suicídio falando abertamente sobre este assunto, pois esta é uma forma de prevenção inicial. Cabe aos educadores e profissionais de saúde orientar toda a comunidade na prevenção do suicídio. Soma-se a isso a necessidade de fortalecer os comportamentos protetores e trabalhar para se lidar positivamente com situações difíceis na vida (PIEDRAHITA et al, 2012). Na 
série, mesmo após o suicídio a escola fictícia continuou abordando o tema de forma inadequada sem realizar prevenção e sem nada fazer de posvenção.

\section{EIXO TEMÁTICO 3 - LUTO POR SUICÍDIO}

Nesse eixo foi identificado o sentimento de culpa por parte dos afetados (pais, profissionais e alunos da escola e os "13 porquês", daquelas pessoas apontadas por Hannah nas fitas como "culpados" por sua morte), a busca por explicações do suicídio (os pais de Hannah chegaram a mover um processo contra a escola por bullying e, ao longo da série, questionavam o porquê da filha ter se suicidado) e dificuldade em lidar com o luto (não foi realizado um funeral para Hannah; Olívia ao conversar com uma desconhecida falou de Hannah como se ela ainda estivesse viva), o que demonstra que vários personagens viviam um luto complicado.

De acordo com Fukumitsu e Kovács (2016), o suicídio provoca sofrimento nas pessoas que ficaram e vivenciam seu impacto, o que foi possível verificar ao longo da série nos pais, profissionais da escola e alunos no geral. Vale ressaltar que o luto por suicídio por si só constitui um fator de risco para o luto complicado, por se tratar de uma morte repentina e violenta envolvida em tabu e preconceito (SILVA, 2009).

Também ficou evidenciado o relato de afastamento e silêncio das pessoas ao redor, conforme pontuado por Fukumitsu e Kovács (2015), pois Olívia, a mãe de Hannah, diz que as pessoas evitavam passar em sua farmácia e até mesmo falar com eles.

O sentimento de culpa também se mostrou bastante presente ao longo dos episódios, assim como a ideia de culpa e de que alguma coisa poderia ter sido feita para evitar o suicídio. A começar pelo título da série, "13 Reasons Why" (que em Português significa "os 13 porquês"), a culpa já fica evidenciada, pois, não só sugere como aponta culpados pela decisão de Hannah de se suicidar. A própria personagem, ao gravar as fitas, aponta as pessoas que são as "culpadas" por sua morte. Cabe ressaltar que o suicídio é uma decisão do próprio sujeito, então, não existem culpados (FUKUMITSU \& KOVÁCS, 2015). Desta forma, percebe-se que o foco da série em nenhum momento parece ser o educativo, e que perdeu-se a oportunidade de pontuar que a personagem estava em sofrimento e que necessitava de ajuda, inclusive quando todos os episódios alimentam a fantasia de que existem culpados pelo suicídio.

Ao longo da série, o personagem Clay vê cenas, reais ou imaginadas, relacionadas com Hannah constantemente, o que é comum no luto por suicídio, já que a pessoa que se suicidou 
pode ocupar um lugar de presença no enlutado através de lembranças e sentimento de culpa, isto é, a pessoa que se matou se mantém presente constantemente nas lembranças de momentos vividos (FUKUMITSU \& KOVÁCS, 2016).

Para Fukumitsu e Kovács (2015), alguns indícios das dificuldades na elaboração do luto são dificuldades financeiras (os pais de Hannah já estavam com dificuldades, mas isso aumentou após a morte da filha), dificuldades no desempenho escolar (Clay e Justin começam a faltar aulas e treinos, respectivamente), aumento do uso de álcool e outras drogas (isso foi visto em vários personagens) e aumento das licenças médicas (Alex começou a apresentar atestados médicos constantemente na escola).

Um dos lutos mais evidenciados, e talvez sentidos, foi o da mãe de Hannah, Olívia, pois era mais visível o seu sofrimento e empenho em buscar explicações para o suicídio da filha. Fukumitsu e Kovács $(2015 ; 2016)$ trazem que a morte por suicídio pode ser ainda mais violenta e traumática para quem encontrou o corpo desfalecido, pois, além de lidar com o luto, a pessoa terá que lidar com o cenário da morte e suas lembranças dessas imagens. No caso da série foi Olívia quem encontrou o corpo de Hannah desfalecido.

Cabe destacar também que um dos afetados pelo suicídio de Hannah, Alex, mostrou alguns indícios de comportamento suicida, chegando até mesmo a uma tentativa. Outro afetado, Justin, relata que quase tentou suicídio e Clay também esteve a ponto de tentar suicídio, sendo impedido por um amigo. Tais tentativas dizem respeito ao risco de suicídio daqueles que foram afetados por suicídio (OMS, 2006).

\section{EIXO TEMÁTICO 4 - ABORDAGEM DA MÍDIA AO SUICÍDIO}

A partir da análise da série, percebe-se que se trata de uma história fictícia, como apontado no início da série, entretanto, a partir das orientações existentes sobre como a mídia deve abordar a temática do suicídio, é possível constatar que houve várias falhas na forma em que o tema foi explorado, valorizando a função midiática em detrimento da educativa e preventiva.

Foi identificado na abordagem da mídia o culto ao armário de Hannah (seu armário da escola virou uma espécie de "altar", onde os alunos diariamente depositavam cartinhas e flores), atribuição de culpa (foram apontados 13 "porquês" de Hannah ter se matado, culpando 12 pessoas por sua escolha), detalhamento da morte (a série mostra, no último episódio, Hannah obtendo o método para morrer, o seu planejamento como a gravação das fitas e mostra a cena do 


\section{CONQGEESSOCIENCIAESOCIEDADE

suicídio detalhadamente) e avisos sobre o conteúdo da série (no início do primeiro episódio há um aviso com alguns atores falando sobre o conteúdo da série e sugerindo que quem estiver passando por problemas como violência sexual, uso de drogas, suicídio e outros, talvez seja melhor não assistir ou assistir com algum adulto confiável e que, se o telespectador sentir que precisa conversar com alguém, falar com seus pais, um amigo, um conselheiro escolar ou um adulto em quem confie ou ligar para um serviço de ajuda local.

A forma como a série foi abordada está em desconformidade com as orientações da Organização Mundial da Saúde (2000) ao mostrar um culto ao armário de Hannah, pois isso soa como uma glorificação à vítima de suicídio e pode sugerir às pessoas vulneráveis que o comportamento suicida é honrado pela sociedade; ao atribuir culpas, pois não existem culpados; ao mostrar a cena do suicídio e o corpo de Hannah e o método utilizado assim como a forma que foi obtido, tendo em vista que isso pode acarretar um Efeito Werther.

Quanto aos avisos sobre o conteúdo da série exibidos no início do primeiro episódio, apesar de alertar quanto ao conteúdo poder ser mobilizador, pode-se inferir que os mesmos não se mostram muito efetivos, uma vez que a pessoa em sofrimento ou com ideação suicida se encontra vulnerável, podendo não ter condições de buscar ajuda, além de serem suscetíveis de reproduzir os comportamentos observados.

No episódio "13 Reasons Why: Além dos Porquês", os produtores falaram que a intenção ao produzir a série era ajudar as pessoas, falar sobre os efeitos de um suicídio, ajudar os pais a prestarem atenção em coisas que podem afetar seus filhos e que houveram psicólogos acompanhando a criação do roteiro e as filmagens para que os atores pudessem ter uma ideia do que se passa na mente de seus personagens e porque eles se comportam assim.

Quanto à explicação de por que fizeram Hannah se matar da forma que foi e por que mostraram a cena, o produtor Brian Yorkey disse que "trabalharam duro para não ser injustificado, mas o objetivo era ser doloroso de assistir porque queriam que ficasse muito claro que não há nada... de qualquer forma... que valha um suicídio". Já a psicóloga Helen Hsu, que participa desse episódio, disse que "a cena do suicídio foi importante para mostrar que não é uma morte bela, nem fácil, e depois a dor para seus pais que são deixados apenas com este terrível fardo".

Apesar das justificativas apresentadas pela produção da série e profissionais de saúde convidados, a OMS (2000) é clara ao abordar que as cenas de suicídio e método utilizado para isso 
não devem ser exibidos por conta do risco de desencadear outros suicídios, o chamado Efeito Werther. Assim, a série, em sua intenção de ajudar as pessoas, pode ter tido um efeito contrário e até mesmo ter sido gatilho para pessoas vulneráveis.

No tocante ao papel da mídia na prevenção do suicídio, a série poderia ter abordado problemas de saúde mental que Hannah pudesse apresentar, deixar mais claro os sinais de alerta, pois estes só são mostrados em seus extremos como bilhetes, mostrar alternativas ao suicídio (OMS, 2000) e até mesmo ter dado um outro desfecho para a série, como por exemplo que Hannah procurasse ajuda e recebesse apoio e com isso desistido de morrer. Talvez assim, se poderia realmente passar a ideia de que, como tanto se fala nas campanhas, "o suicídio não é a solução".

Como ponto positivo, a série ajudou a divulgar o Centro de Valorização à Vida (CVV) como contato onde se pode obter ajuda, ampliou as conversas sobre empatia e trouxe para o centro das discussões esse tema tão tabu em nossa sociedade.

\section{CONSIDERAÇÕES FINAIS/CONCLUSÕES}

Buscamos analisar criticamente a série de streaming "13 Reasons Why" a partir das orientações propostas pela OMS no guia para os profissionais da mídia e foi possível perceber que a série se distancia em vários aspectos dessas orientações, como apontar culpados, evidenciar um culto ao armário de Hannah na escola e mostrar a cena do suicídio e o método utilizado para esse ato, o que consideramos ser capaz de, pelo Efeito Werther, desencadear outros suicídios.

Dentre os desafios, obstáculos e conflitos abordados pela série ao abordar a temática do suicídio, foram identificados dificuldade com o processo de luto, relações interpessoais fragilizadas, relações familiares distantes, falhas de comunicação e falta de habilidades no manejo do luto e acolhimento aos alunos por parte da escola. Sobre os objetivos específicos de como a psicologia pode trabalhar com séries/filmes que abordam a temática do suicídio e propor formas adequadas de como abordar o suicídio na mídia, de forma a promover a saúde mental e prevenir o suicídio, sugerimos que isso seja realizado baseado nas recomendações propostas pela OMS no guia para os profissionais da mídia e com a devida responsabilidade e sensibilidade que esse tema requer. 


\section{cONGEESSOCOENCIA:SOCIEDADE

O presente estudo apresentou uma análise da série ficcional 13 Reasons Why, cujo enredo gira em torno do suicídio da personagem Hannah. Tal análise permitiu perceber que a série, que teve tanta audiência e aumentou os debates sobre suicídio, além de divulgar serviços de apoio como o Centro de Valorização da Vida (CVV), também pecou em vários aspectos e, uma proposta que poderia ser educativa, acabou tornando-se mais de entretenimento.

A mídia, com seu papel de informação deve estar atenta ao abordar temas tabus e delicados como o suicídio e fazer essa abordagem de forma sensível, responsável e de acordo com as orientações da Organização Mundial de Saúde. Isso não significa evitar abordar essa temática, mas fazê-lo de forma a promover a prevenção ao suicídio, a importância dos cuidados em saúde mental e divulgação dos serviços de apoio psicológico e acolhimento.

\section{AGRADECIMENTOS}

Agradecemos à Universidade Estadual do Piauí que, por meio do Programa Institucional de Bolsas de Iniciação Científica, proporcionou o desenvolvimento dessa pesquisa.

\section{REFERÊNCIAS}

ALMEIDA, Ana Filipa. Efeito de Werther. Análise Psicológica, 2000, vol. 18, no 1, p. 37-51.

ASSOCIAÇÃO BRASILEIRA DE PSIQUIATRIA (ABP). Comportamento suicida: conhecer para prevenir (dirigido para profissionais de imprensa). Brasil, 2009.

ASSOCIAÇÃO BRASILEIRA DE PSIQUIATRIA (ABP). Suicídio: informando para prevenir. Brasília, 2014.

BOTEGA, Neury José. Crise suicida: avaliação e manejo. Porto Alegre. Artmed, 2015.

FUKUMITSU, Karina Okajima. Suicídio e Gestalt-terapia. 2ª edição revisada. São Paulo. Digital Publish \& Print Editora, 2013.

FUKUMITSU, Karina Okajima. O psicoterapeuta diante do comportamento suicida. Psicol. USP, São Paulo, v. 25, n. 3, p. 268-273, dez. 2014. Disponível em $<$ http://www.scielo.br/scielo.php?script=sci_arttext\&pid=S010365642014000300270\&Ing=pt\&nrm=iso>. Acesso em 20 nov. 2017.

FUKUMITSU, Karina Okajima; KOVÁCS, Maria Júlia. O luto por suicídios: uma tarefa da posvenção. Revista Brasileira de Psicologia, vol. 2, no 2, p.41-47. Salvador, Bahia, 2015. 
FUKUMITSU, Karina Okajima; KOVÁCS, Maria Júlia. Especificidade sobre processo de luto frente ao suicício. Psico (Porto Alegre). Vol. 47, no 1, p. 3-12. Porto Alegre, 2016. Disponível em:

$<$ http://pepsic.bvsalud.org/scielo.php?script=sci_arttext\&pid=S0103-

$53712016000100002 \&$ Ing=pt\&nrm=iso $>$. Acesso em 20/02/2018.

JACK, B. Goethe's Werther and its effect. Lancet Psychiatry, 2014, vol. 1, no 1, p. 18-19. Disponível em: <http://www.thelancet.com/pdfs/journals/lanpsy/PIIS2215-0366(14)70229-9.pdf> Acesso em $14 / 02 / 2018$.

LOUREIRO, P. R. A., MOREIRA, T. B., \& SACHSIDA, A. (2013). Os efeitos da mídia sobre o suicídio: uma análise empírica para os estados brasileiros. Rio de Janeiro, RJ: Instituto de Pesquisa Econômica Aplicada. Disponível em: http://repositorio.ipea.gov.br/bitstream/11058/2264/1/ TD_1851.pdf Acesso em 11/04/2017

ORGANIZAÇÃO MUNDIAL DA SAÚDE (OMS). Prevenção do suicídio: um manual para profissionais da mídia. Genebra, 2000.

ORGANIZAÇÃO MUNDIAL DA SAÚDE (OMS). Prevenção do suicídio: um recurso para conselheiros. Genebra, 2006.

PIEDRAHITA S, Laura Elvira; PAZ, Karla Mayerling; ROMERO, Ana Maritza. Estrategia de intervención para la prevención del suicidio en adolescentes: la escuela como contexto. Hacia promoc. Salud, Manizales, v.17, n.2, p.136-148, 2012. Disponível em: $<$ http://www.scielo.org.co/scielo.php?script=sci_arttext\&pid=S0121$75772012000200010 \&$ Ing=en\&nrm=iso>. Acessado em 08/08/2018.

PIRKIS, Jane \& BLOOD, Warwick. Suicide and the entertainment media - a critical review. Commonwealth of Australia, Fevereiro de 2010. Disponível em: $<$ http://www.mindframemedia.info/_data/assets/pdf_file/0005/6494/Suicide-and-the-entertainment-media.pdf > Acesso em: $16 / 02 / 2018$.

SILVA, D. E a vida continua... O processo de luto dos pais após o suicídio de um filho. Tese (mestrado). São Paulo. 2009. Pontifícia Universidade Católica de São Paulo.

ZANA, Augusta Rodrigues de Oliveira; KÓVACS, Maria Julia. O Psicólogo e o atendimento a pacientes com ideação ou tentativa de suicídio. Estud. pesqui. psicol., Rio de Janeiro, v. 13, n. 3, p. 897-921, dez. 2013 . Disponível em <http://pepsic.bvsalud.org/scielo.php?script=sci_arttext\&pid=S1808$42812013000300006 \&$ Ing=pt\&nrm=iso>. Acesso em 24/01/2018. 